\title{
Combined analysis of ZAP-70 and CD38 expression in sudanese patients with B-cell chronic lymphocytic leukemia
}

\author{
Ameen Abdulaziz Basabaeen ${ }^{1,6^{*}}$, Enaam Abdelrhman Abdelgader ${ }^{2}$, Othman Saeed BaHashwan ${ }^{3}$, \\ Ebtihal Ahmed Babekir ${ }^{1}$, Nour Mahmoud Abdelateif ${ }^{1}$, Salem Ahmed Bamusa ${ }^{6}$, Saadia Osman Abdelrahim', \\ Osama Ali Altayeb ${ }^{5}$, Eman Abbass Fadul ${ }^{5}$ and Ibrahim Khider Ibrahim ${ }^{1,4}$
}

\begin{abstract}
Objective: To investigate the ZAP-70 and CD38 expressions and their combined expressions in Sudanese B-CLL patients and their relationships with clinical and hematological characteristics as well as the disease staging at presentation.

Results: In the present cross-sectional descriptive study, analysis of ZAP-70 expression showed that 36/110 (32.7\%) patients positively expressed ZAP-70 and insignificant higher presentation in intermediate and at advanced stages as well as no correlation was seen with hematological parameters and clinical features compared with negatively ZAP-70, on the other hand, 41/110 (37.3\%) were CD38 ${ }^{+}$and no significant correlation was shown with the stage at presentation, clinical characteristics (except Splenomegaly, $\mathrm{P}=0.02$ ) and hematological parameters. However, in combined expressions of both ZAP-70 and CD38 together, 20/110 (18.2\%) were concordantly ZAP- $70^{+} / \mathrm{CD}^{2} 8^{+}$, 53/110 (48.2\%) concordantly ZAP-70- $/ \mathrm{CD}^{-} 8^{-}$and 37/110 (33.6\%) either ZAP-70 ${ }^{+}$or CD38 ${ }^{+}$, and these three groups showed insignificant correlation with clinical (except Splenomegaly, $\mathrm{P}=0.03$ ) and hematological parameters, and the stage at presentation. Our data showed the combined analysis of these two markers, lead to classify our patients into three subgroups (either concordant positive, negative or discordant expressions) with statistically insignificant correlation with clinical presentation (except Splenomegaly), hematological parameters and stage at presentation of B-CLL patients.
\end{abstract}

Keywords: B-CLL, ZAP-70, CD38, Combined, Rai, Binet, Hematological, Sudan

\section{Introduction}

B-cell chronic lymphocytic leukemia (B-CLL) is characterized by progressive accumulation of monoclonal, small, mature-appearing $\mathrm{CD} 5^{+} \mathrm{B}$-cells in the peripheral blood, bone marrow and secondary lymphoid tissue [1]. CLL is the most common leukemia in adults in western countries and it is more common in males [2,3]. B-CLL is a heterogeneous disorder characterized by a variable clinical course [4]. In a continual effort to identify

\footnotetext{
*Correspondence: ameenbasabaeen162@gmail.com
}

${ }^{1}$ Department of Hematology, Faculty of Medical Laboratory Sciences, Al Neelain University, Khartoum, Sudan

Full list of author information is available at the end of the article patients with poor prognosis and to facilitate the clinical management of B-CLL [5].

Staging systems have delineated the clinical presentation and natural history of B-CLL and have allowed predicting survival and treatment requirements $[6,7]$. However, the staging systems lack the ability to distinguish prospectively patients with early stage B-CLL that will rapidly progress to aggressive disease from patients destined to remain in early stage for a long period of time [4].

The presence or absence of somatic mutations in the (IgVH) of B-CLL cells has been described as one of the most powerful prognostic factors distinguishing two disease subsets $[8,9]$. The cases with mutated $(\operatorname{IgVH})$ 
genes exhibit a favorable clinical course and they may never require treatment [10]; while patients with unmutated $(\mathrm{IgVH})$ genes are characterized by a reduced survival and responsiveness to chemotherapy $[8,11,12]$. However, determination of $(\mathrm{IgVH})$ mutation is based on DNA sequencing which is not always available for routine clinical use. So, several surrogate markers [13], that correlate with $(\mathrm{IgVH})$ mutational status have been identified. Moreover, CD38 and ZAP-70 expressions have been proposed as less expensive and time-consuming surrogates for $(\mathrm{IgVH})$ mutational status [14, 15]. More recently the combined of ZAP-70 and CD38 expressions analysis provided complementary prognostic information to identify three patient subgroups with good, intermediate and poor prognosis [16]. Many studies showed that $\left(\mathrm{CD} 38^{-} / \mathrm{ZAP}^{-} 70^{-}\right)$group of patients with good prognosis, $\left(\mathrm{CD} 38^{+} / \mathrm{ZAP}-70^{+}\right)$group with poor prognosis, and group $\left(\mathrm{CD} 38^{+} / \mathrm{ZAP}-70^{-}\right)$or $\left.\mathrm{CD} 38^{-} / \mathrm{ZAP}-70^{+}\right)$with intermediate prognosis $[16,17]$.

To the best of our knowledge, this is the first study conducted in Sudan to investigate the combined expressions of both ZAP-70 and CD38 in B-CLL patients and their Correlation with clinical features, hematological parameters and at a stage of presentation. The aim of our study to evaluate the effect of ZAP-70 and CD38 independently as well as combined expression of both together in B-CLL patients and their influence in clinical features, hematological parameters and at a stage of presentation, accordingly our patients are divided into three groups.

\section{Main text}

\section{Methods}

This study was a prospective cross-sectional descriptive study, conducted in Khartoum state, Sudan, in the period from April 2017 to April 2018. A total of 110 blood samples were collected from patients with B-cell CLL. Patients were obtained at Flow Cytometry Laboratory for Leukemia \& Lymphoma Center, Khartoum, Sudan, where they were referred for immunophenotypic diagnosis.

All patients were diagnosed based on clinical history, physical examination, complete blood count, immunophenotypic criteria and B lymphocytes $\geq 5 \times 10^{9} / \mathrm{l}$, according to IWCLL [17]. The stage of the CLL was assessed by Rai and Binet [6, 7] classification. All patients were newly diagnosed without any previous B-CLL treatment; as explained in our previous work [18].

\section{Determination of blood count and immunophenotyping}

Samples were collected in EDTA tubes, complete blood counts were performed by using automated hematological analyzer (SYSMEX- KX-21N, Japan).

The diagnosis of CLL was confirmed for each patient by flow cytometry (EPICS XL Beckman Coulter Flow
Cytometer, Miami, FL, USA), standard protocol of Beckman Coulter [19] was used in fluorescent dye labeled monoclonal antibody for CD45, CD5, CD3, CD19, CD20, CD22, CD23, FMC7, CD79b, kappa, and lambda light chain. A marker was considered positive at a cutoff level of $\geq 30 \%$ according to the $\mathrm{BCSH}$ guideline [20]. A diagnostic scoring system was assessed by Matutes et al. [21, 22]. Absolute B lymphocyte count was obtained by flow cytometry. Expression of ZAP-70 and CD38were performed by flow cytometry, as previously described [18, $23,24]$.

\section{Statistical analysis}

Patient's data was collected by a structural interview questionnaire and from patient's medical records and analyzed by using the (SPSS), version-23. The analysis was done for quantitative variables of B-cell CLL to compare means and variance of means by using T-test, ANOVA and Kruskal-Wallis and Mann-Whitney test as well as correlations with Pearson and Spearman.

\section{Results \\ ZAP-70 and CD38 expression}

ZAP-70 expression was positive in $36 / 110$ (32.7\%) and negative in $74 / 110$ (67.3\%) whereas CD38 was positively expressed in 41/110 (37.3\%) and negative in 69/110 (62.7\%). The correlation of expression of ZAP-70 and CD38 with clinical features, hematological parameter, and stages according to Rai and Binet staging systems are shown in Additional file 1: Tables S1-S3.

\section{Combined ZAP-70 and CD38 expression analysis}

When ZAP-70 and CD38 were combined expressions together, 20/110 (18.2\%) were concordant positive (ZAP$\left.70^{+} \mathrm{CD}^{+} 8^{+}\right), 53 / 110(48.2 \%)$ were concordant negative (ZAP-70- ${ }^{-}$CD38 $8^{-}$), and 37/110 (33.6\%) were discordant. In discordant groups, positivity of ZAP-70 protein without CD38 expression (ZAP-70- ${ }^{-}$D $38^{+}$) was detected in 16 patients (14.5\%), whereas 21 patients $(19.1 \%)$ were CD38-positive but ZAP-70-negative (ZAP-70- ${ }^{-}$D38 ${ }^{+}$). The correlation of combined ZAP-70 and CD38 with clinical features, hematological parameters and stages at presentation according to Rai and Binet staging systems are shown in Tables 1, 2 and 3.

\section{Discussion}

ZAP-70 and CD38 were used as surrogate markers for the mutated and unmutated (IgVH) to facilitate the clinical management of B-CLL.

Considering ZAP-70, using $20 \%$ as the cutoff for positivity, 36/110 (32.7\%) of our patients had positive ZAP70 expression. Nearly similar distribution was seen by Del Giudice et al. [25], Hus et al. [26], D'arena et al. [27] 
Table 1 Combined ZAP-70 and CD38 expression within clinical parameters

\begin{tabular}{lccll}
\hline Parameter(s) & \multicolumn{2}{c}{ Concordant } & Discordant & P* value \\
\cline { 2 - 3 } & +VE no (\%) & -VE no (\%) & No (\%) & \\
\hline Gender & & & & \\
Male & $16(80.0 \%)$ & $38(71.7 \%)$ & $25(67.6 \%)$ & 0.71 \\
Female & $4(20.0 \%)$ & $15(27.3 \%)$ & $12(32.4 \%)$ & \\
Lymphadenopathy & $16(80.0 \%)$ & $34(64.2 \%)$ & $28(75.7 \%)$ & 0.30 \\
Splenomegaly & $14(61.1 \%)$ & $20(43.2 \%)$ & $20(63.4 \%)$ & 0.03 \\
Hepatomegaly & $4(20.0 \%)$ & $7(13.2 \%)$ & $3(8.1 \%)$ & 0.43 \\
No. of lymph areas involved & & & \\
$\leq 3$ & $12(60 \%)$ & $34(64.2 \%)$ & $19(51.4 \%)$ & 0.55 \\
$>3$ & $8(40 \%)$ & $19(35.8 \%)$ & $18(48.6 \%)$ & \\
\hline
\end{tabular}

Except Splenomegaly, there was insignificant correlation between concordant or discordant ZAP-70/CD38 expressions with clinical characteristics

$X^{2}$ test $(n=110), P^{*}$ value significant below 0.05

(28\%, 36.5\% and 36\% respectively), whereas Waheed et al. [28] reported higher expression (60\%) but Gogia et al. [29] and Abdel-Gader et al. [23] reported lower expression $(25 \%)$ and $(22.6 \%)$ in India and Sudan, respectively.
According to meta-analysis done by Liu et al. [30] the role of ZAP-70 expression in the prognosis of B-CLL is unaffected by region. Discrepancies may be due to different [protocols, the antibody used and the cutoff value was used $(10 \%$ or $20 \%)][27,31]$.

In our study, from patients who were ZAP-70 positive, (52.8\%) were at high risk (III, IV) Rai stage, (5.6\%) were at low risk (0) Rai stage. On the other hand, (35\%) were at $\mathrm{C}$ Binet stage and $(30 \%)$ were at A Binet stage at while in ZAP- $70^{-}$patients $(47.3 \%)$ were at high risk (III, IV) stage, $(10.8 \%)$ at low risk (0) stage, $(35.8 \%)$ at Binet C stage, and (35.8\%) at Binet A stage. The lower Percentage of ZAP- $70^{+}$patient presented at low risk (0) Rai stage compared to ZAP- $70^{-}$patients $(5.6 \%$ and $10.8 \%$, respectively) indicated much aggressive disease at presentation in $\mathrm{ZAP}-70^{+}$patient, but was statistically insignificant. While Hus et al. [26], Schroers et al. [16], D'arena et al. [27], Del Giudice et al. [25] and Waheed et al. [28] found that there were significant correlations of ZAP-70 with stage at presentation, our study found no such associations (Additional file 1: Table S3), similar to study that reported by Abdel-Gader et al. [23], and Gogia et al. [29].

Table 2 Means of hematological parameters of combined ZAP-70 and CD38 expressions

\begin{tabular}{lcccc}
\hline $\begin{array}{l}\text { Parameter(s) } \\
\text { Mean } \pm \text { SD }\end{array}$ & \multicolumn{1}{c}{ Concordant } & & Discordant \\
\cline { 2 - 4 } & +VE (\%) & -VE (\%) & (\%) \\
\hline TWBCs $\times 10^{3} / \mu \mathrm{l}$ & $93.4 \pm 73.5$ & $97.2 \pm 76.5$ & $86.4 \pm 76.6$ \\
Platelets $\times 10^{3} / \mu \mathrm{l}$ & $207.7 \pm 88.7$ & $200.3 \pm 118.3$ & $163.4 \pm 89.0$ & 0.80 \\
Absolute lymphocytes $\times 10^{3} / \mu \mathrm{l}$ & $80.1 \pm 69.0$ & $87.5 \pm 73.2$ & $75.6 \pm 63.7$ & 0.17 \\
Monoclonal B lymphocytes $\times 10^{3} / \mu \mathrm{l}$ & $72.0 \pm 67.6$ & $77.78 \pm 67.9$ & $67.5 \pm 66.5$ & 0.73 \\
Hemoglobin $\mathrm{g} / \mathrm{dl}$ & $11 \pm 3$ & $11 \pm 3$ & $11 \pm 2$ & 0.77 \\
\hline
\end{tabular}

There was no significant correlation between concordant or discordant ZAP-70/CD38 expressions with hematological parameters ANOVA test; $(\mathrm{n}=110), P^{*}$ value significant below 0.05

Table 3 Combined ZAP-70 and CD38 expressions according modified Rai and Binet stages

\begin{tabular}{|c|c|c|c|c|}
\hline \multirow[t]{2}{*}{ Parameter(s) } & \multicolumn{2}{|l|}{ Concordant } & \multirow{2}{*}{$\begin{array}{l}\text { Disconcordant } \\
\text { (\%) }\end{array}$} & \multirow[t]{2}{*}{$P^{*}$ value } \\
\hline & +VE (\%) & -VE (\%) & & \\
\hline \multicolumn{5}{|l|}{ Rai stage } \\
\hline Low risk (0) & $1(5 \%)$ & $6(11.3 \%)$ & $3(8.1 \%)$ & 0.72 \\
\hline Intermediate (I, II) & $10(50 \%)$ & $23(43.4 \%)$ & $13(35.1 \%)$ & \\
\hline High risk (III, IV) & $9(45 \%)$ & $24(45.3 \%)$ & $21(56.8 \%)$ & \\
\hline \multicolumn{5}{|l|}{ Binet stage } \\
\hline A & $6(30 \%)$ & $19(35.8 \%)$ & $8(21.6 \%)$ & 0.69 \\
\hline B & $7(35 \%)$ & 15 (28.4\%) & $13(35.2 \%)$ & \\
\hline$C$ & $7(35 \%)$ & $19(35.8 \%)$ & $16(43.2 \%)$ & \\
\hline Total & $20 / 110(18.2 \%)$ & $53 / 110(48.2 \%)$ & $37 / 110$ (33.6\%) & \\
\hline
\end{tabular}

Analysis of combined ZAP-70 and CD38 expressions according modified Rai and Binet stages showed no significant correlation Kruskal-Wallis test; $(\mathrm{n}=110) . P^{*}$ value significant below 0.05 
Regarding CD38 expression, using 30\% cutoff for positivity, 41/110(37.3\%) patients were positive, nearly same as that reported by Abdelgader et al. [24] and Gogia et al. [29], (36.4\% and 36.25\%) respectively, whereas Waheed et al. [28] reported higher expression (60\%), but D'arena et al. [27] reported lower expression (29\%). Expression variations may be due to different [protocols, an antibody used and variation of cutoff used for positivity (7\%, 20\% and 30\%)] [25, 27]. Nearly same distribution trends in Rai and Binet stages as in ZAP-70 were noticed for CD38 (Additional file 1: Table S3).

Hus et al. [26], Schroers et al. [16], D'arena et al. [27], Del Giudice et al. [25] and Waheed et al. [28] found that there were significant correlations of CD38 with the stage at presentation but our study found no such associations (Additional file 1: Table S3), same as the study that reported by Abdelgader et al. [24], and Gogia et al. [29], but noteworthy, Abdelgader et al. [24] only found that there was significant association between CD38 and hemoglobin concentration by using cutoff level $7 \%$ [24] and Schroers et al. [16]. Hus et al. [26] however, found there were significant differences in hematological parameter with expressions of ZAP-70 and CD38. In our study, the only exception was Splenomegaly $(\mathrm{P}=0.021)$ with CD38 expression and no significant correlations of ZAP-70 and CD38 expressions with age, sex, hematological parameters and clinical findings at presentation were found (Additional file 1: Table S1-S3), which was inconsistent with Abdelgader et al. [24], Gogia et al. [29], Waheed et al. [28].

The correlation of ZAP-70 with CD38 showed a strong association ( $\mathrm{P}=0.003)$ (Additional file 2: Figure $\mathrm{S} 1$ ), which agree with the results of the literature. Accordingly, our patients were categorized into three subgroups, two concordant $\left(\mathrm{ZAP}-70^{+} \mathrm{CD} 38^{+}\right),\left(\mathrm{ZAP}-70^{-} \mathrm{CD} 38^{-}\right)$, and discordant group where only ZAP-70 or CD38 is positive. Our separate analysis of both discordant groups $\left(\mathrm{ZAP}-70^{-} \mathrm{CD} 38^{+}\right)$and $\left(\mathrm{ZAP}-70^{+} \mathrm{CD}^{-} 8^{-}\right)$revealed that there were no clinical or biological differences so they were treated as one discordant group.

When comparing between $\left(\mathrm{ZAP}-70^{+} \mathrm{CD} 38^{+}\right)$and (ZAP-70- CD38-), Hus et al. [26], Schroers et al. [16], D'arena et al. [27] found that there was significant correlation of $\left(\mathrm{ZAP}-70^{+} \mathrm{CD} 38^{+}\right)$with clinical presentation and hematological parameters while Gogia et al. [29] failed to find such associations in $80 \mathrm{~B}$-CLL patients of whom $56 \%$ were concordant $\left(\mathrm{ZAP}-70^{+} \mathrm{CD} 38^{+}\right)$. The correlation with discordant groups was much less significant through previous studies. Furthermore, Hus et al. [26], Schroers et al. [26], D'arena et al. [27] found that there was a significant correlation between $\left(\mathrm{ZAP}-70^{+} \mathrm{CD} 38^{+}\right.$) with the survival rates and treatment free interval. This association was not evaluated in this study.
In our study, of 20/110 concordant (ZAP- $70^{+} \mathrm{CD} 38^{+}$) patients, 19/20 (95\%) were at intermediate (I, II) or advanced (III, IV) Rai stage comparing to only $1 / 20$ $(5 \%)$ in early stage (0), and in $37 / 110$ concordant (ZAP$70^{-} \mathrm{CD} 38^{-}$) patients $34 / 37$ (81.9\%) were at intermediate (I, II) or high risk (III, IV) Rai stage. Our results showed no significant difference between concordant (ZAP- $70^{+}$ $\left.\mathrm{CD} 38^{+}\right)$and $\left(\mathrm{ZAP}-70^{-} \mathrm{CD} 38^{-}\right)$with Rai or Binet stage at presentation and the correlation with discordant groups was much less significant (Table 3); the same conclusion was reported by Gogia et al. [29], Assem et al. [32]. The majority of our patients 100/110 (91\%) were presented at the intermediate or advanced stage; this can explain the comparable correlation between the two concordant groups and with discordant groups.

With the exception of Splenomegaly $(\mathrm{P}=0.037)$, regarding age, sex, clinical findings, and hematological parameters means, there were no significant correlations between concordant ZAP-70 and CD38 expressions or with discordant expression of both (Tables 1, 2 and 3), same as Gogia et al. [29], Waheed et al. [28] reported, and in contrast to Hus et al. [26], Del Giudice et al. [25] who found that there were significant differences in the most hematological parameter between concordant groups.

Noticeably, Splenomegaly was correlated with positive expression of CD38 but not ZAP-70, and the combination of both $\left(\mathrm{ZAP}-70^{+} \mathrm{CD} 38^{+}\right)$was still significant which may imply the significance of concordant analysis of ZAP-70 and CD38 as a better prognostic marker better than each one independently. Frequencies of concordant and discordant expressions of ZAP-70 and CD38 in some important studies are shown in Additional file 1: Table S4.

Conclusion, our study showed $\mathrm{CD} 38^{+}$was significantly associated with Splenomegaly. While expressions of ZAP-70 and CD38 were not statistically associated with significantly more advanced stages at Rai and Binet of B-CLL patients at presentation. In addition, the combination of these two markers together leads to classifying our patients into three subgroups (concordant positive, negative and discordant groups) which is statistically insignificant with clinical presentation (except Splenomegaly), hematological parameters and stage at presentation of B-CLL patients.

\section{Limitations}

Limitations are worth to mention such as sampling method which depends on voluntary participation, patients were not followed up for progression, survival rates and response to treatment after diagnosis confirmation. Finally, our study does not include studying the prognostic value of ZAP-70 or CD38 independently or even combined the expression of both together, indeed 
all limitations that are mentioned above should be taken in consideration in order to the interpretation of our results.

\section{Additional files}

Additional file 1: Table S1. Frequencies of clinical parameters according to ZAP-70 and CD38 expressions. Table S2. Means of hematological parameters according to ZAP-70 and CD38 expressions. Table S3. ZAP-70 and CD38 expressions in modified Rai and Binet stages. Table S4. Combined ZAP-70 and CD38 expressions in some previous studies and present study.

Additional file 2: Figure S1. Relationship between ZAP-70 and CD38 expressions in $110 \mathrm{~B}-\mathrm{CLL}$ patients.

\section{Abbreviations}

CLL: chronic lymphocytic leukemia; IWCLL: International workshop of chronic lymphocytic leukemia; CD: cluster of differentiation; IgHV: immunoglobulin heavy chain variable region; ZAP-70: zeta chain associated protein; EDTA: ethylenediamine tetraacetic acid; SPSS: Statistical Package for Social Sciences; WBC: white blood cell; RBC: red blood cell; BCSH: British Committee for Standards in Hematology.

\section{Acknowledgements}

We would like to thank the staff of Hematology Department at Al Neelain University for facilities and supporting and we are grateful to the staff of Flow Cytometry Laboratory for Leukemia \& Lymphoma for their collaboration. Finally special thanks to the patients for being cooperative, despite their pains.

\section{Authors' contributions}

$A A B, E A A$ and IKI conceived the study design, participated in data collection, performed the statistical analysis, interpreted the results, and revised the manuscript. OSB, EAB, NMA, SAB and SOA participated in the statistical analysis, and drafted the manuscript. OAA and EAF participated in the data collection, carried out the laboratory work, and prepared the results. All authors read and approved the final manuscript.

\section{Funding}

The research did not receive any fund or financial support.

\section{Availability of data and materials}

The individual data are available in the archives of the Flow Cytometry for Leukemia \& Lymphoma Diagnosis, Khartoum, Sudan and can be obtained from the corresponding author on request.

\section{Ethics approval and consent to participate}

Ethical clearance was obtained from the Institutional Review Board at Al Neelain University. Principal investigator obtained written informed consent from all participants prior to their inclusion in the study.

\section{Consent for publication}

Not applicable.

\section{Competing interests}

The authors declare that they have no competing interests.

\section{Author details}

${ }^{1}$ Department of Hematology, Faculty of Medical Laboratory Sciences, Al Neelain University, Khartoum, Sudan. ${ }^{2}$ Department of Pathology, Faculty of Medicine, Al Neelain University, Khartoum, Sudan. ${ }^{3}$ Department of Family Medicine, Faculty of Medicine, University of Gezira, Wad Medani, Sudan. ${ }^{4}$ Department of Hematology, School of Medical Sciences, University Sains Malaysia, Health Campus, 16150 Kubang Kerian, Kelantan, Malaysia. ${ }^{5}$ Flow Cytometry Laboratory for Leukemia \& Lymphoma Diagnosis, Khartoum, Sudan. ${ }^{6}$ Ministry of Health \& Population, Hadhramout, Yemen.
Received: 25 April 2019 Accepted: 18 May 2019

Published online: 23 May 2019

\section{References}

1. Chiorazzi N, Rai KR, Ferrarini M. Chronic lymphocytic leukemia. N Engl J Med. 2005;352(8):804-15.

2. Inamdar KV, Bueso-Ramos CE. Pathology of chronic lymphocytic leukemia: an update. Ann Diagn Pathol. 2007;11(5):363-89.

3. Yee KW, O'Brien SM. Chronic lymphocytic leukemia: diagnosis and treatment. Mayo Clin Proc. 2006;81(8):1105-29.

4. Keating MJ, Chiorazzi N, Messmer B, Damle RN, Allen SL, Rai KR, Ferrarini M, Kipps TJ. Biology and treatment of chronic lymphocytic leukemia. Hematology. 2003:2003:153-75.

5. Shanafelt TD, Geyer SM, Kay NE. Prognosis at diagnosis: integrating molecular biologic insights into clinical practice for patients with CLL. Blood. 2004;103(4):1202-10.

6. Rai KR, Sawitsky A, Cronkite EP, Chanana AD, Levy RN, Pasternack BS. Clinical staging of chronic lymphocytic leukemia. Blood. 1975;46(2):219-34.

7. Binet JL, Auquier A, Dighiero G, Chastang C, Piguet H, Goasguen J, Vaugier G, Potron G, Colona P, Oberling F, et al. A new prognostic classification of chronic lymphocytic leukemia derived from a multivariate survival analysis. Cancer. 1981;48(1):198-206.

8. Hamblin TJ, Davis Z, Gardiner A, Oscier DG, Stevenson FK. Unmutated $\lg V(H)$ genes are associated with a more aggressive form of chronic lymphocytic leukemia. Blood. 1999;94(6):1848-54.

9. Oscier DG, Thompsett A, Zhu D, Stevenson FK. Differential rates of somatic hypermutation in $\mathrm{V}(\mathrm{H})$ genes among subsets of chronic lymphocytic leukemia defined by chromosomal abnormalities. Blood. 1997:89(11):4153-60

10. Oscier DG, Gardiner AC, Mould SJ, Glide S, Davis ZA, Ibbotson RE, Corcoran MM, Chapman RM, Thomas PW, Copplestone JA, et al. Multivariate analysis of prognostic factors in CLL: clinical stage, IGVH gene mutational status, and loss or mutation of the p53 gene are independent prognostic factors. Blood. 2002;100(4):1177-84.

11. Krober A, Seiler T, Benner A, Bullinger L, Bruckle E, Lichter P, Dohner H, Stilgenbauer S. V(H) mutation status, CD38 expression level, genomic aberrations, and survival in chronic lymphocytic leukemia. Blood. 2002;100(4):1410-6.

12. Damle RN, Wasil T, Fais F, Ghiotto F, Valetto A, Allen SL, Buchbinder A, Budman D, Dittmar K, Kolitz J, et al. Ig V gene mutation status and CD38 expression as novel prognostic indicators in chronic lymphocytic leukemia. Blood. 1999;94(6):1840-7.

13. Hamblin TJ. Searching for surrogates for IGHV mutations in chronic lymphocytic leukemia. Leuk Res. 2011;35:1432-5.

14. Hamblin TJ, Orchard JA, Ibbotson RE, Davis Z, Thomas PW, Stevenson FK, Oscier DG. CD38 expression and immunoglobulin variable region mutations are independent prognostic variables in chronic lymphocytic leukemia, but CD38 expression may vary during the course of the disease. Blood. 2002;99(3):1023-9.

15. Crespo M, Bosch F, Villamor N, Bellosillo B, Colomer D, Rozman M, Marce S, Lopez-Guillermo A, Campo E, Montserrat E. ZAP-70 expression as a surrogate for immunoglobulin-variable-region mutations in chronic lymphocytic leukemia. N Engl J Med. 2003;348(18):1764-75.

16. Schroers R, Griesinger F, Trumper L, Haase D, Kulle B, Klein-Hitpass L, Sellmann L, Duhrsen U, Durig J. Combined analysis of ZAP-70 and CD38 expression as a predictor of disease progression in B-cell chronic lymphocytic leukemia. Leukemia. 2005;19(5):750-8.

17. Hallek M, Cheson BD, Catovsky D, Caligaris-Cappio F, Dighiero G, Dohner $H$, Hillmen P, Keating MJ, Montserrat E, Rai KR, et al. Guidelines for the diagnosis and treatment of chronic lymphocytic leukemia: a report from the International Workshop on Chronic Lymphocytic Leukemia updating the National Cancer Institute-Working Group 1996 guidelines. Blood. 2008;111(12):5446-56.

18. Basabaeen AA, Abdelgader EA, Babekir EA, Eltayeb NH, Altayeb OA, Fadul EA, Bahashwan OS, Ibrahim IK. Clinical presentation and hematological profile among young and old chronic lymphocytic leukemia patients in Sudan. BMC Res Notes. 2019;12(1):202.

19. Beckman Coulter I. COULTER ${ }^{\circledR}$ EPICS $^{\circledR}$ XL $^{\text {TM }}$ Flow Cytometer. 2010. 
20. Oscier D, Dearden C, Eren E, et al. Guidelines on the diagnosis, investigation and management of chronic lymphocytic leukaemia. Br J Haematol. 2012;159(5):541-64

21. Matutes E, Owusu-Ankomah K, Morilla R, Garcia Marco J, Houlihan A, Que TH, Catovsky D. The immunological profile of B-cell disorders and proposal of a scoring system for the diagnosis of CLL. Leukemia. 1994;8(10):1640-5.

22. Moreau EJ, Matutes E, A'Hern RP, Morilla AM, Morilla RM, OwusuAnkomah KA, Seon BK, Catovsky D. Improvement of the chronic lymphocytic leukemia scoring system with the monoclonal antibody SN8 (CD79b). Am J Clin Pathol. 1997;108(4):378-82.

23. Abdel-Gader EA-R, Eltayeb NH, Eltahir TA, Altayeb OA, Fadul EA, Rahman EMA, Merghani TH. ZAP-70 expression in B-chronic lymphocytic leukemia in Sudanese patients. Sudan J Med Sci. 2018;13(4):230-9. https://doi. org/10.18502/sjms.v13i4.3593.

24. Abdelgader EA, Eltayeb NH, Eltahir TA, Altayeb OA, Fadul EA, Abdel Rahman EM, Merghani TH. Evaluation of CD38 expression in Sudanese patients with chronic lymphocytic leukemia. BMC Res Notes. 2018;11(1):815.

25. Del Giudice I, Morilla A, Osuji N, Matutes E, Morilla R, Burford A, Maravelaki S, Owusu-Ankomah K, Swansbury J, A'hern R. Chain associated protein 70 and CD38 combined predict the time to first treatment in patients with chronic lymphocytic leukemia. Cancer Interdiscip Int J Am Cancer Soc. 2005;104(10):2124-32

26. Hus I, Podhorecka M, Bojarska-Junak A, Roliński J, Schmitt M, Sieklucka M, Wąsik-Szczepanek E, Dmoszyńska A. The clinical significance of ZAP-70 and CD38 expression in B-cell chronic lymphocytic leukaemia. Ann Oncol. 2006;17(4):683-90.

27. D'arena G, Tarnani M, Rumi C, Vaisitti T, Aydin S, De Filippi R, Perrone F, Pinto A, Chiusolo P, Deaglio S. Prognostic significance of combined analysis of ZAP-70 and CD38 in chronic lymphocytic leukemia. Am J Hematol. 2007:82(9):787-91.

28. Waheed R, Mahana N, Kassem N, EL-Deeb S. ZAP70 and CD38 as prognostic markers for chronic lymphocytic leukemia in Egyptian patients. Med J Cairo Univ. 2015:83(1):627-32.

29. Gogia A, Sharma A, Raina V, Kumar L, Gupta R, Kumar R. Prevalence of ZAP-70 and CD 38 in Indian chronic lymphocytic leukemia patients. Indian J Cancer. 2013;50(4):333.

30. Liu Y, Wang Y, Yang J, Bi Y, Wang H. ZAP-70 in chronic lymphocytic leukemia: a meta-analysis. Clin Chim Acta. 2018;483:82-8.

31. Orchard JA, Ibbotson RE, Davis Z, Wiestner A, Rosenwald A, Thomas PW, Hamblin TJ, Staudt LM, Oscier DG. ZAP-70 expression and prognosis in chronic lymphocytic leukaemia. Lancet. 2004;363(9403):105-11.

32. Assem M, Hamid TA, Kohla A, Arsanyos S. The prognostic significance of combined expression of ZAP-70 and CD38 in chronic lymphocytic leukemia. J Egypt Nat Cancer Inst. 2009;21(4):287-97.

\section{Publisher's Note}

Springer Nature remains neutral with regard to jurisdictional claims in published maps and institutional affiliations.
Ready to submit your research? Choose BMC and benefit from:

- fast, convenient online submission

- thorough peer review by experienced researchers in your field

- rapid publication on acceptance

- support for research data, including large and complex data types

- gold Open Access which fosters wider collaboration and increased citations

- maximum visibility for your research: over $100 \mathrm{M}$ website views per year

At $\mathrm{BMC}$, research is always in progress.

Learn more biomedcentral.com/submissions 